\title{
Barriers to avoiding fast-food consumption in an environment supportive of unhealthy eating
}

\author{
Lukar E Thornton ${ }^{1, *}$, Robert W Jeffery ${ }^{2}$ and David A Crawford ${ }^{1}$ \\ ${ }^{1}$ Centre for Physical Activity and Nutrition Research, School of Exercise and Nutrition Sciences, Deakin \\ University, 221 Burwood Highway, Burwood, Victoria 3125, Australia: ${ }^{2}$ University of Minnesota Obesity \\ Prevention Center, School of Public Health, University of Minnesota, Minneapolis, MN, USA
}

Submitted 19 December 2011: Final revision received 30 August 2012: Accepted 18 0ctober 2012: First published online 27 November 2012

\begin{abstract}
Objective: To investigate factors (ability, motivation and the environment) that act as barriers to limiting fast-food consumption in women who live in an environment that is supportive of poor eating habits.

Design: Cross-sectional study using self-reports of individual-level data and objectively measured environmental data. Multilevel logistic regression was used to assess factors associated with frequency of fast-food consumption.

Setting: Socio-economically disadvantaged areas in metropolitan Melbourne, Australia.

Subjects: Women ( $n$ 932) from thirty-two socio-economically disadvantaged neighbourhoods living within $3 \mathrm{~km}$ of six or more fast-food restaurants. Women were randomly sampled in 2007-2008 as part of baseline data collection for the Resilience for Eating and Activity Despite Inequality (READI) study.

Results: Consuming low amounts of fast food was less likely in women with lower perceived ability to shop for and cook healthy foods, lower frequency of family dining, lower family support for healthy eating, more women acquaintances who eat fast food regularly and who lived further from the nearest supermarket. When modelled with the other significant factors, a lower perceived shopping ability, mid levels of family support and living further from the nearest supermarket remained significant. Among those who did not perceive fruits and vegetables to be of high quality, less frequent fast-food consumption was further reduced for those with the lowest confidence in their shopping ability.

Conclusions: Interventions designed to improve women's ability and opportunities to shop for healthy foods may be of value in making those who live in high-risk environments better able to eat healthily.
\end{abstract}

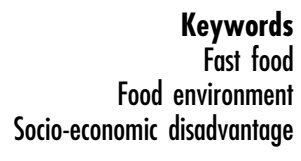

Keywords

Food environment Socio-economic disadvantage
The majority of fast foods are energy-dense and low in micronutrients ${ }^{(1)}$. Both the supply of and the demand for fast food have increased in recent decades, and more frequent fast-food consumption has been shown to be a consistent risk factor for obesity and other adverse health conditions $^{(2-4)}$

A known determinant of fast-food use is individual- and area-level socio-economic disadvantage, i.e. individuals with lower income or who are from socio-economically disadvantaged areas tend to purchase and consume more fast food ${ }^{(5-7)}$. While this may partly be attributable to the fact that such foods are less expensive than healthier alternatives (or at least perceived to be), other factors must also be involved as well since people living in disadvantaged neighbourhoods tend to consume more fast food, independent of their individual socio-economic position ${ }^{(5)}$. The food environments in socio-economically disadvantaged areas are often said to be more supportive of unhealthy choices ${ }^{(8)}$. For example, a greater abundance of fast-food stores in disadvantaged areas is one plausible contributor to increased fast-food use as the environment supports more opportunities for purchasing such products $^{(9,10)}$. Prior studies have confirmed that those with easier access to fast-food restaurants consume more fast food ${ }^{(11-13)}$, particularly if these residents have low income ${ }^{(14)}$. This also supports the assertion that a greater convenience and lower time cost are key determinants of fast-food use ${ }^{(15-18)}$.

Conceptual models of health behaviours posit that behaviours are influenced by an individual's ability to make healthy behaviour choices, his/her motivation to do so and environmental opportunities ${ }^{(19,20)}$. Thus, where people have the same environmental opportunities, individual differences in health behaviours remain due to variations in ability and motivation. These factors can operate at multiple levels (e.g. individual, household, social) and many of 
these have already been linked to healthier eating. For example, an individual's enjoyment of cooking and his/her cooking skills are inversely associated with fast-food use $^{(15-17,21)}$ but positively associated with fruit and vegetable intakes ${ }^{(22)}$. Members of a household and other social connections can positively influence the motivation to eat and provide healthy foods if they directly encourage and model healthy eating ${ }^{(23,24)}$, while having regular family meals has been shown to facilitate healthier eating ${ }^{(25)}$. Outside the home, other built environment factors such as the presence of healthy food stores may discourage the purchasing of fast food through the provision of healthier alternatives, while perceptions of local food environments also play a role ${ }^{(26)}$. What remains largely unknown is to what extent such factors are important to a healthier diet in an environment that is supportive of frequent fast-food consumption.

In the present study we report on factors related to ability, motivation and environmental opportunities that may explain the variability in fast-food consumption. We limit our analysis to women living in socio-economically disadvantaged neighbourhoods with a high number of fast-food stores. Understanding additional barriers to infrequent fast-food consumption in an environment that already supports higher use may provide important intervention alternatives for behavioural change that may be easier to implement than changing the built environment (e.g. reducing the number of fast-food restaurants in an area).

\section{Methods}

\section{The Resilience for Eating and Activity Despite Inequality study}

The current paper examines data collected in 2007-2008 as part of the baseline data collection within the Resilience for Eating and Activity Despite Inequality (READI) study ${ }^{(24)}$. Forty urban and forty rural suburbs were randomly selected from the most disadvantaged tertile of suburbs within Victoria, Australia. Suburb disadvantage was defined by the 2001 Socio-Economic Index for Areas (SEIFA) Index of Relative Disadvantage, which is calculated from numerous area-level variables including (but not limited to) the proportion of low-income households in the area, the proportion of people who do not speak English well and the proportion of people with no post-school qualifications $^{(27)}$. READI survey measures were validated where possible, all measures were pilot-tested and 1-week testretest reliability was established.

The Australian electoral roll (registration on the electoral roll is compulsory for all Australian citizens) was used to randomly identify 150 women aged $18-45$ years from the eighty areas ( $n 11$ 940; some included areas had $<150$ eligible women). Respondents replied to a postal invitation to complete a questionnaire and after excluding those who failed to meet eligibility criteria (e.g. respondents who moved from the sampled neighbourhood prior to completing the survey, were not the intended participant, withdrew their data after completing the survey, or were $<18$ or $>46$ years old), there were 4349 eligible participants (39\% of those who were delivered a survey). Analyses in the present study were further restricted to women who lived in urban areas ( $n$ 2015; $46 \cdot 5 \%$ of sample) because the environmental exposures and how these influence consumption vary greatly between urban and rural neighbourhoods.

\section{Fast-food restaurant exposure}

Ten fast-food chains were used in our measure of fastfood restaurant exposure, each of which has more than 100 outlets in Australia: Dominos Pizza, Eagle Boys Pizza, KFC, Hungry Jacks, Nandos, Pizza Haven, Pizza Hut, McDonalds, Red Rooster and Subway. Using the geographic information system ArcGIS 9.3 (ESRI, Redlands, CA, USA), we undertook a count of fast-food restaurants within a 3-km road network distance ${ }^{(28)}$ from each individual's household location. Three kilometres was chosen because this distance corresponds with prior evidence that the majority of food shopping is undertaken within this distance from home ${ }^{(29,30)}$. The median number of fast-food restaurants within $3 \mathrm{~km}$ of where individuals lived in the present study was six. Respondents were considered to have high exposure if they had access to six or more fast-food restaurants within $3 \mathrm{~km}$ ( $n$ 1019; $50 \cdot 6 \%$ of the urban sample).

\section{Fast-food consumption}

Fast-food consumption was derived using two questions: 'In the past month, how often have you had the following: (a) fast food (e.g. McDonalds, KFC) and (b) pizza?' Response categories were: (i) never or less than once/ month; (ii) 1-3 times/month; (iii) once/week; (iv) 2-4 times/ week; (v) 5-6 times/week; (vi) once/d; (vii) 2-3 times/d; (viii) 4-5 times/d; (ix) $\geq 6$ times/d. Response categories were converted to weekly equivalents, with never or less than once/month considered as $0 \cdot 25$ /week and 1-3 times/ month considered as $0 \cdot 5 /$ week. As the fast-food restaurant exposure measure included both fast-food outlets and pizza outlets, consumption of these two items was combined. The final consumption variable was coded as: (i) infrequent (consumed fast food/pizza $<1$ time/week); (ii) frequent (consumed fast food/pizza $\geq 1$ time/week).

\section{Independent variables}

Five variables related to motivation and ability were examined. At the individual level, two factors were examined: (i) 'How confident are you that you could shop regularly for healthy nutritious foods over the next year?' and (ii) 'How confident are you that you could prepare/ cook healthy nutritious foods over the next year?' (response categories for both: 5-point Likert scale ranging from 'not at 
all confident' to 'extremely confident'; collapsed for analysis as a result of data distribution to 'not at all/slightly confident', 'moderately confident' and 'very/extremely confident'). At the household level, we explored: (i) 'How often do you usually eat dinner with your family?' (response categories: 'rarely/never', '<1 time/week', '1-3 times/week', '4-6 times/week', 'every day' and 'not applicable'; collapsed for analysis to ' $\leq 3$ times/week', '4-6 times/week' and 'every day'); and (ii) family support for healthy eating based on how often (during the past year) members of their family: (a) ate healthy low-fat foods with them; (b) encouraged them to eat healthy low-fat foods; and (c) discouraged them from eating unhealthy foods (response categories for each: 5-point Likert scale from 'never' to 'very often' plus a 'not applicable' option which was re-coded to ' 1 ' (never) after confirming that this response indicated respondents had no immediate family and so did not receive support from family; scores were summed (Cronbach's $\alpha=0 \cdot 75$ ) and coded as 'low' (sum of scores =3-6), 'mid' (7-10) and 'high' (11-15)). The sociallevel factor explored was: (i) 'Lots of women I know eat fast food' (response categories: 5-point Likert scale from 'strongly disagree' to 'strongly agree'; collapsed for analysis to 'disagree', 'neutral' and 'agree').

The environmental factors explored were both real and perceived. These were assessed to determine whether access to healthier alternatives was protective against fast-food consumption. To assess whether supermarkets and greengrocers were easily accessible, we used ArcGIS $9 \cdot 3$ to determine the proximity ${ }^{(28)}$ to these stores along a network path. A tertile measure was created for these to reflect if the closest store was within $0.8 \mathrm{~km}$, between 0.8 and $1.6 \mathrm{~km}$ or further than $1.6 \mathrm{~km}$. Perceptions were based on the following three questions ${ }^{(31)}$ : (i) 'A large selection of fruit and vegetables is available in my neighbourhood'; (ii) 'The fresh fruit and vegetables in my neighbourhood are of high quality'; and (iii) 'A large selection of low-fat products is available in my neighbourhood' (response categories for each: 5-point Likert scale from 'strongly disagree' to 'strongly agree'; collapsed for analysis to 'do not agree' and 'agree').

\section{Covariates}

The following covariates were considered potential confounders and controlled for in analysis: age of respondent, country of birth (coded as Australia; overseas), marital status (married/de facto; previously married; never married), number of children under the age of 18 years living in the household (none; one; two; three or more), education (low (= did not complete Year 12); medium (= completed Year 12 (high school), trade certificate or diploma); high $(=$ completed tertiary education $)$ ) and employment status (working full-time; working part-time; not currently in paid employment). Selection of key covariates was informed by prior work conducted within Melbourne-based studies $^{(7,32)}$.

\section{Statistical analysis}

Analysis was undertaken on complete case data with a final sample of 932 participants from socio-economic disadvantaged urban areas with access to six or more fast-food restaurants (eighty-seven participants were dropped for missing values). Descriptive and multilevel analyses were undertaken using the statistical software package Stata 11.2. As respondents were clustered within suburbs, multilevel logistic regression was undertaken using the user-written GLLAMM function which allows for maximum likelihood estimation of multilevel models ${ }^{(33)}$. Results from the multilevel analysis were presented as odds ratios with 95\% confidence intervals which estimate the odds of infrequent fast-food consumption compared with those who consume at least weekly. For the independent variables explored, higher numbers of participants were more often in the response category that reflected 'healthier' behaviours. As a result, these were used as the reference category for analysis. Therefore a statistically significant odds ratio below one indicates that if a woman is not in the optimal response category then the likelihood of her having low fast-food consumption is reduced. Thus this indicates that, when statistically significant, these factors are acting as barriers to avoiding fast-food consumption. In Model 1, all independent variables are analysed separately adjusted for confounders. For Model 2, we analysed all significant factors from Model 1 together to determine the relative contribution of these on fast-food consumption.

\section{Results}

Sample characteristics are presented in Table 1. The mean age of the women in the sample was $33 \cdot 3$ (sD 7.6) years. The majority of the study sample was born in Australia, married, living in households without children and had completed high school and/or further education. About half of the sample (49\%) was working full-time.

Table 2 shows that half of the sample consumed fast food less than once weekly (51\%). A higher percentage of infrequent consumers were found among those with the highest confidence in their ability to shop for $(62 \%)$ or cook/prepare healthy food $(62 \%)$. The majority of those who ate dinner with their family every day $(54 \%)$ or had high family support for healthy eating (57\%) ate fast food on an infrequent basis, as did those who disagreed they knew lots of other women who eat fast food regularly (60\%). Only one-third (33\%) of those who had their nearest supermarket further than $1.6 \mathrm{~km}$ away ate fast food infrequently compared with over half of those having their nearest supermarket within this distance. A higher percentage of respondents within $0.8 \mathrm{~km}$ of their nearest greengrocer were infrequent fast-food consumers (60\%) compared with those with the nearest greengrocer within $0.8-1.6 \mathrm{~km} \mathrm{(49 \% )}$ and further than $1.6 \mathrm{~km}(40 \%)$. A slightly higher percentage 
Table 1 Characteristics of the study respondents: women ( $n$ 932) from socio-economically disadvantaged areas in metropolitan Melbourne, Australia, 2007-2008

\begin{tabular}{|c|c|c|}
\hline Characteristic & Mean & SD \\
\hline \multirow[t]{2}{*}{ Age (years) } & $33 \cdot 3$ & $7 \cdot 6$ \\
\hline & $n$ & $\%$ \\
\hline \multicolumn{3}{|l|}{ Country of birth } \\
\hline Australia & 739 & $79 \cdot 3$ \\
\hline Overseas & 193 & $20 \cdot 7$ \\
\hline \multicolumn{3}{|l|}{ Marital status } \\
\hline Married/de facto & 526 & $56 \cdot 4$ \\
\hline Previously married & 80 & $8 \cdot 6$ \\
\hline Never married & 326 & $35 \cdot 0$ \\
\hline \multicolumn{3}{|c|}{ Number of children under the age of 18 years living in household } \\
\hline None & 516 & $55 \cdot 3$ \\
\hline One & 159 & $17 \cdot 1$ \\
\hline Two & 173 & $18 \cdot 6$ \\
\hline Three or more & 84 & $9 \cdot 0$ \\
\hline \multicolumn{3}{|l|}{ Education } \\
\hline Low & 127 & $13 \cdot 6$ \\
\hline Medium & 434 & $46 \cdot 6$ \\
\hline High & 371 & $39 \cdot 8$ \\
\hline \multicolumn{3}{|l|}{ Employment status } \\
\hline Working full-time & 454 & $48 \cdot 7$ \\
\hline Working part-time & 188 & $20 \cdot 2$ \\
\hline Not currently in paid employment & 290 & $31 \cdot 1$ \\
\hline
\end{tabular}

of those with positive perceptions about their local food environment ate fast food infrequently compared with frequently.

When modelled independent of each other (Model 1), each of the individual, household and social factors was associated with infrequent fast-food consumption as was the proximity to the nearest supermarket (Table 3). Barriers to infrequent fast-food consumption were identified among those with a lower confidence to shop for healthy foods, a lower confidence to cook/prepare healthy foods, who ate dinner with their family $\leq 3$ times/ week, with lower levels of family support for healthy eating behaviours and who knew other women who ate fast food often. With regard to environmental factors, those who lived further than $1.6 \mathrm{~km}$ from their nearest supermarket were less likely to be infrequent fast-food consumers than those living within $0 \cdot 8 \mathrm{~km}$. No statistically significant associations were found for the other environmental factors.

In Model 2 each of the statistically significant factors was analysed simultaneously (Table 3). Compared with women with the highest confidence in their ability to shop for healthy food, those with moderate ( $O R=0.52$; $95 \%$ CI $0.33,0 \cdot 82$ ) or the lowest confidence (OR $0 \cdot 46$; $95 \%$ CI $0 \cdot 24,0 \cdot 88$ ) had a significantly lower odds of being an infrequent fast-food consumer. Likewise, having a mid level of family support for healthy eating was a significant barrier to consuming fast-food infrequently $(\mathrm{OR}=0 \cdot 62$; $95 \%$ CI $0 \cdot 44,0 \cdot 87$ ) compared with those with the highest support, although no significant association was found among those with the lowest family support. Finally, compared with women within $0.8 \mathrm{~km}$ of their nearest supermarket, those living further than $1.6 \mathrm{~km}$ away remained significantly less likely to consume fast food on an infrequent basis (OR $=0 \cdot 58 ; 95 \%$ CI 0.35, 0.96).

As confidence in shopping may be influenced by the other environmental factors explored (real and perceived), interaction terms were run for these (results not shown). A significant interaction was found between shopping confidence and perception of fruit and vegetable quality. Consequently, we explored confidence to shop for healthy food stratified by perceived quality of fruits and vegetables. Among those women who did not agree fruits and vegetables were of high quality, the likelihood of infrequent fast-food consumption was further reduced for those with the lowest confidence in their shopping ability $(\mathrm{OR}=0 \cdot 34 ; 95 \%$ CI $0 \cdot 12,0 \cdot 97$; results not shown).

\section{Discussion}

A number of multilevel conceptual frameworks exist related to health behaviours and more specifically eating behaviours. The present study focused on three factors that are included in most of these models: ability to make healthy choices, motivation and environmental opportunities $^{(19,20)}$. Our study explored the extent to which additional barriers related to ability, motivation and the environment further contributed to the likelihood of avoiding infrequent fast-food consumption when the environment already supports the purchasing and consumption of this product through high levels of fast-food restaurant access. Factors identified among women as barriers to healthy food choices included having a lower 
Table 2 Ability, motivation and environmental factors by frequency of fast-food consumption among women ( $n$ 932) from socioeconomically disadvantaged areas in metropolitan Melbourne, Australia, 2007-2008

\begin{tabular}{|c|c|c|c|}
\hline & \multicolumn{2}{|c|}{ Infrequent fast-food consumption ( $<1$ time/week) } & \multirow[b]{2}{*}{$P\left(\chi^{2}\right)$} \\
\hline & $n$ & $\%$ & \\
\hline All respondents & 932 & $50 \cdot 6$ & \\
\hline \multicolumn{4}{|l|}{ Ability } \\
\hline \multicolumn{4}{|l|}{ Confidence to shop for healthy food } \\
\hline Very/extremely & 546 & $61 \cdot 5$ & \\
\hline Moderately & 236 & $38 \cdot 6$ & \\
\hline Not at all/slightly & 150 & $30 \cdot 0$ & $<0.001$ \\
\hline \multicolumn{4}{|l|}{ Confidence to cook/prepare healthy food } \\
\hline Very/extremely & 497 & $62 \cdot 0$ & \\
\hline Moderately & 291 & $40 \cdot 9$ & \\
\hline Not at all/slightly & 144 & $31 \cdot 3$ & $<0.001$ \\
\hline \multicolumn{4}{|l|}{ Motivation } \\
\hline \multicolumn{4}{|l|}{ Frequency of dinner with family } \\
\hline Every day & 351 & $54 \cdot 4$ & \\
\hline 4-6 times/week & 224 & $45 \cdot 1$ & \\
\hline$\leq 3$ times/week & 357 & $50 \cdot 4$ & 0.092 \\
\hline \multicolumn{4}{|l|}{ Family support for healthy eating } \\
\hline High tr & 336 & $57 \cdot 4$ & \\
\hline Mid & 374 & $43 \cdot 9$ & \\
\hline Low & 222 & $51 \cdot 8$ & 0.001 \\
\hline \multicolumn{4}{|c|}{ Lots of women I know eat fast food often } \\
\hline Disagree & 332 & $60 \cdot 2$ & \\
\hline Neutral & 299 & $48 \cdot 8$ & \\
\hline Agree & 301 & $41 \cdot 9$ & $<0.001$ \\
\hline \multicolumn{4}{|l|}{ Environment } \\
\hline \multicolumn{4}{|l|}{ Supermarket proximity } \\
\hline Closest within $0.8 \mathrm{~km}$ & 307 & $57 \cdot 6$ & \\
\hline Closest between 0.8 and $1.6 \mathrm{~km}$ & 468 & $51 \cdot 9$ & \\
\hline Closest further than $1.6 \mathrm{~km}$ & 157 & $33 \cdot 1$ & $<0.001$ \\
\hline \multicolumn{4}{|l|}{ Greengrocer proximity } \\
\hline Closest within $0.8 \mathrm{~km}$ & 329 & $59 \cdot 6$ & \\
\hline Closest between 0.8 and $1.6 \mathrm{~km}$ & 375 & $49 \cdot 1$ & \\
\hline Closest further than $1.6 \mathrm{~km}$ & 228 & $40 \cdot 4$ & $<0.001$ \\
\hline \multicolumn{4}{|c|}{ Large selection of F\&V available in neighbourhood } \\
\hline Agree & 771 & $51 \cdot 5$ & \\
\hline Do not agree & 161 & $46 \cdot 6$ & $0 \cdot 257$ \\
\hline \multicolumn{4}{|l|}{ F\&V available are of high quality } \\
\hline Agree & 578 & $51 \cdot 7$ & \\
\hline Do not agree & 354 & $48 \cdot 9$ & 0.397 \\
\hline \multicolumn{4}{|c|}{ Large selection of low-fat products available } \\
\hline Agree & 663 & $52 \cdot 9$ & \\
\hline Do not agree & 269 & $45 \cdot 0$ & 0.028 \\
\hline
\end{tabular}

F\&V, fruits and vegetables.

confidence in their ability to either shop for or cook healthy foods, a lower motivation to eat healthily through having less frequent family meals, less family support for healthier eating, knowing other women who often ate fast food regularly and reduced environmental opportunities to access alternative foods through reduced supermarket access. Relative to other explanatory factors, a low confidence in shopping ability acted as the strongest barrier to avoiding fast-food consumption and this was further strengthened when we assessed only women who also perceived locally available fruits and vegetables were not of good quality. It is important to note that each of these results was not accounted for by demographic and socio-economic differences as these were adjusted for in analyses.

The impact of environment on health indicators such as obesity has become a strong focus of recent research $^{(34,35)}$ and has led to common use of the term 'obesogenic' environments. We limited our analysis to areas with a single obesogenic environmental factor: a high number of fast-food outlets. Consequently, this environment is conducive to higher fast-food consumption through providing increased opportunities and we were therefore able to identify additional factors that further discouraged the avoidance of fast food. As the built environment in established areas is difficult to change, the present study provides key insights into other potential avenues for intervention at the community level that may be easier to implement, although we do acknowledge the complexities associated with nutritionrelated interventions ${ }^{(36)}$.

While we recognise an individual's ability to engage in healthy behaviours can be dictated by a myriad of factors, in the current study we assessed skills related to shopping for and the preparation of healthy foods. Confidence in 
Table 3 Multilevel logistic regression results: associations between explanatory factors and infrequent fast-food consumption among women ( $n$ 932) from socio-economically disadvantaged areas in metropolitan Melbourne, Australia, 2007-2008

\begin{tabular}{|c|c|c|c|c|c|c|}
\hline & \multicolumn{2}{|c|}{ Model 1} & \multirow[b]{2}{*}{$P$ for trend } & \multicolumn{2}{|c|}{ Model 2} & \multirow[b]{2}{*}{$P$ for trenc } \\
\hline & OR & $95 \% \mathrm{Cl}$ & & OR & $95 \% \mathrm{Cl}$ & \\
\hline \multicolumn{7}{|l|}{ Ability } \\
\hline \multicolumn{7}{|l|}{ Confidence to shop for healthy food } \\
\hline Very/extremely & $1 \cdot 00$ & - & & 1.00 & - & \\
\hline Moderately & $0 \cdot 41^{\star * *}$ & $0.29,0.58$ & & $0.52^{\star *}$ & $0 \cdot 33,0.82$ & \\
\hline Not at all/slightly & $0 \cdot 31^{\star \star \star}$ & $0 \cdot 20,0.48$ & $<0.001$ & $0 \cdot 46^{\star}$ & $0 \cdot 24,0.88$ & 0.006 \\
\hline \multicolumn{7}{|c|}{ Confidence to cook/prepare healthy food } \\
\hline Very/extremely & $1 \cdot 00$ & - & & $1 \cdot 00$ & - & \\
\hline Moderately & $0 \cdot 48^{\star \star *}$ & $0.35,0.66$ & & $0 \cdot 78$ & $0.51,1 \cdot 22$ & \\
\hline Not at all/slightly & $0 \cdot 32^{\star \star \star}$ & $0.21,0.50$ & $<0.001$ & 0.68 & $0 \cdot 35,1 \cdot 33$ & $0 \cdot 206$ \\
\hline \multicolumn{7}{|l|}{ Motivation } \\
\hline \multicolumn{7}{|l|}{ Frequency of dinner with family } \\
\hline Every day & $1 \cdot 00$ & - & & $1 \cdot 00$ & - & \\
\hline 4-6 times/week & $0 \cdot 72$ & $0.49,1.05$ & & $0 \cdot 70$ & $0 \cdot 48,1 \cdot 02$ & \\
\hline$\leq 3$ times/week & $0 \cdot 68^{*}$ & $0.48,0.98$ & 0.034 & $0 \cdot 75$ & $0.51,1.09$ & $0 \cdot 107$ \\
\hline \multicolumn{7}{|l|}{ Family support for healthy eating } \\
\hline High & $1 \cdot 00$ & - & & $1 \cdot 00$ & - & \\
\hline Mid & $0 \cdot 54^{\star \star *}$ & $0 \cdot 39,0.75$ & & $0 \cdot 62^{* *}$ & $0 \cdot 44,0.87$ & \\
\hline Low & 0.69 & $0 \cdot 46,1 \cdot 01$ & $0 \cdot 016$ & $0 \cdot 79$ & $0 \cdot 53,1 \cdot 20$ & $0 \cdot 129$ \\
\hline \multicolumn{7}{|c|}{ Lots of women I know eat fast food often } \\
\hline Disagree & $1 \cdot 00$ & - & & $1 \cdot 00$ & - & \\
\hline Neutral & $0 \cdot 78$ & $0 \cdot 56,1 \cdot 10$ & & $0 \cdot 91$ & $0 \cdot 64,1 \cdot 30$ & \\
\hline Agree & $0 \cdot 65^{\star}$ & $0.46,0.92$ & 0.016 & $0 \cdot 71$ & $0.50,1.03$ & 0.070 \\
\hline \multicolumn{7}{|l|}{ Environment } \\
\hline \multicolumn{7}{|l|}{ Supermarket proximity } \\
\hline Closest within $0.8 \mathrm{~km}$ & $1 \cdot 00$ & - & & $1 \cdot 00$ & - & \\
\hline Closest between 0.8 and $1.6 \mathrm{~km}$ & $1 \cdot 08$ & $0 \cdot 75,1 \cdot 54$ & & $1 \cdot 14$ & $0 \cdot 79,1 \cdot 65$ & \\
\hline Closest further than $1.6 \mathrm{~km}$ & $0 \cdot 56^{\star}$ & $0.34,0.92$ & 0.049 & $0 \cdot 58^{\star}$ & $0.35,0.96$ & 0.081 \\
\hline \multicolumn{7}{|l|}{ Greengrocer proximity } \\
\hline Closest within $0.8 \mathrm{~km}$ & $1 \cdot 00$ & - & & & & \\
\hline Closest between 0.8 and $1.6 \mathrm{~km}$ & $1 \cdot 08$ & $0 \cdot 74,1 \cdot 61$ & & & & \\
\hline Closest further than $1.6 \mathrm{~km}$ & $0 \cdot 86$ & $0.53,1 \cdot 39$ & 0.555 & & & \\
\hline \multicolumn{7}{|c|}{ Large selection of $F \& V$ available in neighbourhood } \\
\hline Agree & $1 \cdot 00$ & - & & & & \\
\hline Do not agree & $0 \cdot 89$ & $0.62,1.30$ & & & & \\
\hline \multicolumn{7}{|l|}{ F\&V available are of high quality } \\
\hline Agree & $1 \cdot 00$ & - & & & & \\
\hline Do not agree & 1.07 & $0 \cdot 79,1 \cdot 44$ & & & & \\
\hline \multicolumn{7}{|c|}{ Large selection of low-fat products available } \\
\hline Agree & $1 \cdot 00$ & - & & & & \\
\hline Do not agree & $0 \cdot 81$ & $0 \cdot 60,1 \cdot 11$ & & & & \\
\hline
\end{tabular}

Model 1, each predictor modelled separately; Model 2, each significant predictor modelled together; F\&V, fruits and vegetables.

Reference group: those who consume frequently.

${ }^{\star} P \leq 0.05,{ }^{* \star} P \leq 0.01,{ }^{* \star} P \leq 0.001$.

ability to shop for healthy foods remained significant relative to all other factors, suggesting this may be a key avenue to promotion of healthier eating. The skills required for healthy shopping are underappreciated, as not everyone has the nutritional knowledge or ability to understand food labels ${ }^{(37,38)}$. Furthermore, financial and time pressures may lead to food purchasers choosing less healthy alternatives, even when shopping in a supermarkets, as they believe these are cheaper options and quicker to prepare ${ }^{(16,39)}$. By promoting healthier shopping practices, interventions may be able to make substantial changes to the eating practices of both the individual and other family members when the majority of the food supplied to them is purchased by a main household food shopper. Two such interventions are currently underway in Australia, the 'SHOP Smart 4 Health' (SHOP Smart) study and the 'Supermarket Healthy Eating for Life' (SHELF) study ${ }^{(40)}$, that aim to improve the healthiness of food purchases made in supermarkets through a skill-building approach (SHELF also includes a price reduction component). While confidence in ability to cook and prepare healthy meals was also significant, results were attenuated to null when modelled with other factors suggesting that this may be less important relative to shopping. Previously, van der Horst and colleagues reported lower cooking skills among males ${ }^{(17)}$. Given our sample consisted of women aged with a mean age of 33 years, this provides a plausible explanation as to why we found shopping skills to be more important than cooking skills.

As we believed that shopping confidence may be influenced by other features of the food environment, we tested interaction effects on these. Only perceived fruit and vegetable quality was significant and stratified analysis on this variable revealed that the likelihood of being an infrequent fast-food consumer was further reduced 
among those with the lowest shopping skills when they also believed fruits and vegetables available were not of good quality. We have no objective measure of quality in our study; nevertheless, it raises an important point that boosting confidence to shop for healthy foods may be challenging in certain environments.

Motivation to eat healthier can act through an individual's determination but is also likely to be largely influenced by family members and social contacts. In the present study, we looked at three factors that likely relate to motivation at the family and social levels. At the family level, we investigated frequency of eating dinner with the family as this has previously been linked to healthier eating ${ }^{(25)}$. We conceptualised that individuals who eat dinner more regularly with their family may be more motivated to prepare healthier meals (or have healthier meals supplied for them) than those who eat alone or at different times to other family members, as this latter situation may result in family members seeking a more convenient and potentially less healthy alternative. For households with children, a greater confidence and interest in cooking skills taught through school-based classes ${ }^{(41)}$ may translate into a greater frequency of family meals if the children become more interested in and assist with meal preparation. Further, this may also create higher family support for healthy eating, a factor we found to be important in limiting fast-food consumption and is in congruence with past evidence ${ }^{(23)}$. Outside the home, knowing other women who eat fast food often was associated with lower odds of consuming fast food infrequently independent of confounders but not of the other explanatory variables. Being in a social situation where others are eating fast food is a known contributor to fast-food use ${ }^{(24)}$ as it could lower the motivation to avoid this option. Thus, motivational interventions may need to be targeted beyond the individual and at a larger organisational or community level.

Both objective and perceived environmental factors were tested to assess their relationship with fast-food consumption in the sample. Prior studies demonstrate that health outcomes can be improved through access to healthier foods, even when unhealthy options are present ${ }^{(34,42)}$. Our descriptive findings suggested that living close to either a supermarket or greengrocer may encourage lower rates of fast-food consumption; however, this relationship held true only for supermarket access in the analytical models adjusted for demographic and socio-economic covariates. Although not equivocal, there is a growing evidence base to suggest supermarket access encourages healthier diet-related behaviours ${ }^{(43,44)}$. Our present study further supports this by demonstrating that a greater geographic proximity to the nearest supermarket may act as a barrier to being an infrequent fast-food consumer when the environment contains large numbers of fast-food outlets. No differences were detected for the environmental perception variables. While prior work indicates that perception can influence dietary behaviours ${ }^{(45)}$, in the present instance the findings support the notion that building skills in food shopping or improving physical access to supermarkets may be a more effective way to improve dietary behaviours than changing perceptions.

By including only women in socio-economically disadvantaged neighbourhoods with access to a high number of fast-food outlets we have reduced the variability in the unhealthy food stores women are exposed to, allowing us to better focus on ability, motivational and other food environment aspects associated with fast-food consumption frequency. This provides novel information on potentially important avenues to promote dietary change in socio-economically disadvantaged populations. We do however acknowledge weaknesses in our study. First, while examples of fast food were provided, there may be some mismatch between the types of fast food individuals reported consuming and the stores used to define fast-food exposure. Further, statements around 'healthy eating' and 'low-fat foods' were not defined, which may have led to some inconsistencies in reporting. Second, while we have limited our sample to those with high exposure to fast food in their local neighbourhood, fast food can be bought in many other areas including near work and social locations. Future research is needed to collect data that will provide more detailed information on the role of the local food environment in food purchasing decisions relative to other places visited throughout the day. Third, our sample is limited to women and the factors influencing a male's decision to consume fast food are likely to vary. However, despite social changes women remain the most likely person to purchase and prepare food for households ${ }^{(46)}$ and are therefore important to study given the influence they exert on the diet of other household members, particularly children. Finally, we acknowledge that the response rate (39\%) may reduce the generalisability of our findings. However, this issue is not as problematic in our study of associations in a specific sub-population as it may be in a study that was attempting to establish population prevalence.

\section{Conclusions}

Many food environments in socio-economically disadvantaged areas support increased fast-food consumption through the greater presence of fast-food restaurants. A skillbased approach targeted at women's ability to shop for healthy foods presents a potentially effective strategy to reduce the consumption of unhealthy fast-food products, as does providing support for those with restricted supermarket access. Further research is required to assess differences in individual-level explanatory factors when environmental exposures vary.

\section{Acknowledgements}

Sources of funding: The READI study was funded by the Australian National Health and Medical Research Council 
(ID 374241) and approved by the Deakin University Human Research Ethics Committee (approval number EC 91-2006; June 2006). L.E.T. was supported by an Alfred Deakin Postdoctoral Research Fellowship. R.W.J. was supported by the University of Minnesota Obesity Prevention Center and the National Institute of Diabetes and Digestive and Kidney Diseases (grant DK50456). D.A.C. was supported by a VicHealth Senior Research Fellowship. Conflicts of interest: No conflicts of interests are declared. Authors' contributions: L.E.T. conceptualised the study design, undertook the analysis, and wrote the first draft of this paper. R.W.J. and D.A.C. contributed to the study design and redrafting of the paper. Each author read and approved the final version of this manuscript. Acknowledgements: The authors are grateful to Michelle Jackson for managing the READI fieldwork and to Rebecca Roberts for her assistance with the geographic information mapping work.

\section{References}

1. Stender S, Dyerberg J \& Astrup A (2007) Fast food: unfriendly and unhealthy. Int J Obes (Lond) 31, 887-890.

2. Jeffery RW \& French SA (1998) Epidemic obesity in the United States: are fast foods and television viewing contributing? Am J Public Health 88, 277-280.

3. Duffey KJ, Gordon-Larsen P, Steffen LM et al. (2009) Regular consumption from fast food establishments relative to other restaurants is differentially associated with metabolic outcomes in young adults. J Nutr 139, 2113-2118.

4. Pereira MA, Kartashov AI, Ebbeling CB et al. (2005) Fast-food habits, weight gain, and insulin resistance (the CARDIA study): 15-year prospective analysis. Lancet $\mathbf{3 6 5}$, 36-42.

5. Thornton LE, Crawford DA \& Ball K (2010) Neighbourhood socioeconomic variation in women's diet: the role of nutrition environments. Eur J Clin Nutr 64, 1423-1432.

6. French SA, Harnack L \& Jeffery RW (2000) Fast food restaurant use among women in the Pound of Prevention study: dietary, behavioral and demographic correlates. Int J Obes Relat Metab Disord 24, 1353-1359.

7. Thornton LE, Bentley RJ \& Kavanagh AM (2011) Individual and area-level socioeconomic predictors of fast food purchasing. J Epidemiol Community Health 65, 873-880.

8. Fraser LK, Edwards KL, Cade J et al. (2010) The geography of fast food outlets: a review. Int J Environ Res Public Health 7, 2290-2308.

9. Macdonald L, Cummins S \& Macintyre S (2007) Neighbourhood fast food environment and area deprivation substitution or concentration? Appetite 49, 251-254.

10. Pearce J, Blakely T, Witten K et al. (2007) Neighborhood deprivation and access to fast-food retailing: a national study. Am J Prev Med 32, 375-382.

11. Thornton LE, Bentley RJ \& Kavanagh AM (2009) Fast food purchasing and access to fast food restaurants: a multilevel analysis of VicLANES. Int J Behav Nutr Phys Act 6, 28.

12. Moore LV, Diez Roux AV, Nettleton JA et al. (2009) Fast-food consumption, diet quality, and neighborhood exposure to fast food: the multi-ethnic study of atherosclerosis. Am J Epidemiol 170, 29-36.

13. Li F, Harmer P, Cardinal BJ et al. (2009) Obesity and the built environment: does the density of neighborhood fast-food outlets matter? Am J Health Promot 23, 203-209.

14. Boone-Heinonen J, Gordon-Larsen P, Kiefe CI et al. (2011) Fast food restaurants and food stores: longitudinal associa- tions with diet in young to middle-aged adults: the CARDIA study. Arch Intern Med 171, 1162-1170.

15. Dave JM, An LC, Jeffery RW et al. (2009) Relationship and attitudes towards fast food and frequency of fast-food intake in adults. Obesity (Silver Spring) 17, $1164-1170$.

16. Welch N, McNaughton SA, Hunter W et al. (2009) Is the perception of time pressure a barrier to healthy eating and physical activity among women? Public Health Nutr 12, 888-895.

17. van der Horst K, Brunner TA \& Siegrist M (2011) Fast food and take-away food consumption are associated with different lifestyle characteristics. J Hum Nutr Diet 24, 596-602.

18. Rydell SA, Harnack LJ, Oakes JM et al. (2008) Why eat at fast-food restaurants: reported reasons among frequent consumers. J Am Diet Assoc 108, 2066-2070.

19. Rothschild ML (1999) Carrots, sticks, and promises: a conceptual framework for the management of public health and social issue behaviors. J Mark 63, 24-37.

20. Brug J (2008) Determinants of healthy eating: motivation, abilities and environmental opportunities. Fam Pract 25, i50-i55.

21. Dunn KI, Mohr P, Wilson CJ et al. (2011) Determinants of fast-food consumption. An application of the Theory of Planned Behaviour. Appetite 57, 349-357.

22. Crawford D, Ball K, Mishra G et al. (2007) Which foodrelated behaviours are associated with healthier intakes of fruits and vegetables among women? Public Health Nutr 10, 256-265.

23. Dunn KI, Mohr PB, Wilson CJ et al. (2008) Beliefs about fast food in Australia: a qualitative analysis. Appetite 51, 331-334.

24. Ball K, Jeffery RW, Abbott G et al. (2010) Is healthy eating behavior contagious: associations of social norms with physical activity and healthy eating. Int J Behav Nutr Phys Act 7, 86.

25. Neumark-Sztainer D, Hannan PJ, Story M et al. (2003) Family meal patterns: associations with sociodemographic characteristics and improved dietary intake among adolescents. J Am Diet Assoc 103, 317-322.

26. Lucan SC \& Mitra N (2012) Perceptions of the food environment are associated with fast-food (not fruitand-vegetable) consumption: findings from multi-level models. Int J Public Health 57, 599-608.

27. Australian Bureau of Statistics (2003) Census of Population and Housing: Socio-Economic Indexes for Areas (SEIFA). Canberra: ABS.

28. Thornton LE, Pearce JR \& Kavanagh AM (2011) Using Geographic Information Systems (GIS) to assess the role of the built environment in influencing obesity: a glossary. Int J Behav Nutr Phys Act 8, 71.

29. Hillier A, Cannuscio CC, Karpyn A et al. (2011) How far do low-income parents travel to shop for food? Empirical evidence from two urban neighborhoods. Urban Geogr 32, 712-729.

30. Cairns S (1995) Travel for food shopping: the fourth solution. Traffic Eng Control 36, 411-418.

31. Mujahid MS, Diez Roux AV, Morenoff JD et al. (2007) Assessing the measurement properties of neighborhood scales: from psychometrics to ecometrics. Am J Epidemiol 165, 858-867.

32. Thornton LE, Crawford DA \& Ball K (2011) Who is eating where? Findings from the SocioEconomic Status and Activity in Women (SESAW) study. Public Health Nutr 14, 523-531.

33. Rabe-Hesketh S, Skrondal A \& Pickles A (2005) Maximum likelihood estimation of limited and discrete dependent variable models with nested random effects. J Econometrics 128, 301-323. 
34. Morland KB \& Evenson KR (2009) Obesity prevalence and the local food environment. Health Place 15, 491-495.

35. Giskes K, van Lenthe F, Avendano-Pabon M et al. (2011) A systematic review of environmental factors and obesogenic dietary intakes among adults: are we getting closer to understanding obesogenic environments? Obes Rev 12, e95-e106.

36. Gedrich K (2003) Determinants of nutritional behaviour: a multitude of levers for successful intervention? Appetite $\mathbf{4 1}$, 231-238.

37. Fitzgerald N, Damio G, Segura-Perez S et al. (2008) Nutrition knowledge, food label use, and food intake patterns among Latinas with and without type 2 diabetes. J Am Diet Assoc 108, 960-967.

38. Ball K, Crawford D \& Mishra G (2006) Socio-economic inequalities in women's fruit and vegetable intakes: a multilevel study of individual, social and environmental mediators. Public Health Nutr 9, 623-630.

39. Inglis V, Ball K \& Crawford D (2005) Why do women of low socioeconomic status have poorer dietary behaviours than women of higher socioeconomic status? A qualitative exploration. Appetite 45, 334-343.

40. Ball K, McNaughton SA, Mhurchu CN et al. (2011) Supermarket Healthy Eating for Life (SHELf): protocol of a randomised controlled trial promoting healthy food and beverage consumption through price reduction and skillbuilding strategies. BMC Public Health 11, 715.

41. Caraher M, Dixon P, Lang T et al. (1999) The state of cooking in England: the relationship of cooking skills to food choice. Br Food J 101, 590-609.

42. Rundle A, Neckerman KM, Freeman L et al. (2009) Neighborhood food environment and walkability predict obesity in New York City. Environ Health Perspect 117, 442-447.

43. Morland K, Wing S \& Diez Roux A (2002) The contextual effect of the local food environment on residents' diets: the atherosclerosis risk in communities study. Am J Public Health 92, 1761-1767.

44. Moore LV, Diez Roux AV, Nettleton JA et al. (2008) Associations of the local food environment with diet quality - a comparison of assessments based on surveys and geographic information systems: the multi-ethnic study of atherosclerosis. Am J Epidemiol 167, 917-924.

45. Inglis V, Ball K \& Crawford D (2008) Socioeconomic variations in women's diets: what is the role of perceptions of the local food environment? J Epidemiol Community Health 62, 191-197.

46. Coveney J (2002) What does research on families and food tell us? Implications for nutrition and dietetic practice. Nutr Diet 59, 113-119. 